\title{
Intercomparison of Simulation Models for CO2 Disposal in Underground Storage Reservoirs
}

\author{
Karsten Pruess ${ }^{1}$, Chin-Fu Tsang ${ }^{1}$, David Law ${ }^{2}$, and Curt Oldenburg ${ }^{1}$ \\ ${ }^{1}$ Earth Sciences Division, E.O. Lawrence Berkeley National Laboratory \\ One Cyclotron Rd., MS 90-1116, Berkeley, CA 94720, U.S.A. \\ 2 Alberta Research Council \\ 250 Karl Clark Rd., Edmonton, Alberta T6N 1E4, Canada \\ e-mail: CO2sim@1bl.gov \\ Internet: http://esd.lbl.gov/GEOSEQ/
}

\begin{abstract}
An intercomparison study between simulation codes for terrestrial sequestration of $\mathrm{CO} 2$ is proposed. The objectives are, on the one hand, to focus and evaluate key processes through numerical simulation and, on the other, to explore the strengths of different codes and achieve acceptance of such codes for use in the development of geologic systems for $\mathrm{CO} 2$ disposal. This will be carried out through the study of a series of test problems by groups using their simulation codes. A progression from simple and uncoupled to increasingly complex and coupled problems is envisioned. The proposed study will attempt to involve interested technical groups worldwide, and will proceed through an iterative process of problem definition, solution comparison, discussion and refinement. The Internet will be used as a medium for communicating and organizing activities, and for a flexible exchange of information and documentation of results. In addition, it is planned to hold a series of workshops. The present write-up includes an initial set of eight proposed test problems and represents the first step in the process. Readers are encouraged to communicate with us at the email address above to indicate their interest and to provide suggestions and input.
\end{abstract}

\section{INTRODUCTION}

Geologic sequestration of $\mathrm{CO} 2$ can be accomplished by separating $\mathrm{CO} 2$ from flue gases and subsequently injecting it into a variety of storage reservoirs, including brine aquifers, producing or depleted oil and gas reservoirs, and coalbeds. Mathematical models and numerical simulation tools will play an important role in evaluating the feasibility of $\mathrm{CO} 2$ storage in subsurface reservoirs, in designing and analyzing field tests, and in designing and operating geologic $\mathrm{CO} 2$ disposal systems. In order to establish credibility for numerical simulators as practical engineering 
tools, it is necessary to demonstrate that they can model accurately and reliably the important physical and chemical processes that are taking place in the system of interest.

The purpose of the code intercomparison study outlined here is to evaluate key processes in $\mathrm{CO} 2$ geologic disposal and to contribute to the acceptance of numerical simulators as viable tools for modeling $\mathrm{CO} 2$ disposal. To initiate the study we propose a preliminary set of simulation problems that are intended to cover some of the important phenomena and mechanisms arising in geologic sequestration of $\mathrm{CO} 2$. We envision an interactive process through which different technical groups with interests and capabilities relevant to geologic disposal of $\mathrm{CO} 2$ will participate in defining, solving, refining, and augmenting simulation problems. Code intercomparison studies have been successfully used as a means for establishing confidence in simulation tools in related technical fields such as petroleum engineering (Firoozabadi and Thomas, 1989) and geothermal reservoir engineering (Stanford, 1980), and in nuclear waste management (Larsson, 1992; Chapman et al., 1994; Jing et al., 1995; Stephansson et al., 1996).

Depending on the storage reservoir of interest and the composition of the waste gas stream (pure $\mathrm{CO} 2$ vs. mixtures of $\mathrm{CO} 2$ with other gases), injection of $\mathrm{CO} 2$ in geologic formations may give rise to a number of physical and chemical phenomena, such as miscible or immiscible displacement of native fluids, dissolution of injected fluids into reservoir fluids, changes in effective stress with associated porosity and permeability change and the possibility of inducing seismic activity, chemical interactions between fluids and solids, and nonisothermal effects. Key issues arising in process simulation include (1) thermodynamics of sub- and supercritical CO2, and PVT properties of mixtures of $\mathrm{CO} 2$ with other fluids, including (saline) water, oil, and natural gas; (2) fluid mechanics of single and multi-phase flow when $\mathrm{CO} 2$ is injected into aquifers, oil reservoirs, and natural gas reservoirs; (3) coupled hydro-chemical effects due to interactions between $\mathrm{CO} 2$, reservoir fluids, and primary mineral assemblages; and (4) coupled hydro-mechanical effects, such as porosity and permeability change due to increased fluid pressures from $\mathrm{CO} 2$ injection. These issues can be tracked through a matrix of property and process issues for different $\mathrm{CO} 2$ storage reservoirs as shown in Table 1.

Additional topics that need to be addressed include space and time discretization and their impacts on the solution of the underlying mathematical model, and the dependence of processes and parameters on space and time scale. The code intercomparison study should progress from relatively simple, uncoupled problems that address specific issues to increasingly complex problems in which several effects would occur simultaneously. Ultimately it would be desirable to achieve a comprehensive coverage of all process aspects and couplings. The coverage of issues 
achieved through the eight simulation problems proposed in this report is shown by entering the problem numbers into appropriate positions in Table 1. Simulation capabilities for CO2 injection into coalbeds are still in an early stage of development. No coalbed-related test problems are proposed in the present report, but they may be included in future problem sets.

Table 1. Matrix of Code Intercomparison Problems and Issues

\begin{tabular}{|l|c|c|c|c|c|}
\hline $\begin{array}{c}\text { property/process } \\
\text { storage reservoir }\end{array}$ & PVT data & fluid flow & $\begin{array}{c}\text { transport } \\
\text { diffusion, } \\
\text { dispersion) }\end{array}$ & $\begin{array}{c}\text { chemical } \\
\text { reactions }\end{array}$ & $\begin{array}{c}\text { mechanical } \\
\text { couplings }\end{array}$ \\
\hline \hline brine aquifer & $3,4,7$ & $3,4,6,7$ & & 5 & 6 \\
\hline oil & 8 & 8 & 8 & & \\
\hline gas & 1,2 & 1,2 & 1,2 & & \\
\hline coalbed & & & & & \\
\hline
\end{tabular}

Process issues and available and needed modeling capabilities are quite different for the different types of potential $\mathrm{CO} 2$ storage reservoirs. For example, aquifer disposal of $\mathrm{CO} 2$ would most likely occur at conditions that are not too far from the critical point of $\mathrm{CO} 2\left(\mathrm{P}_{\text {crit }}=73.82\right.$ bar, $\mathrm{T}_{\text {crit }}=31.04{ }^{\circ} \mathrm{C}$; Vargaftik, 1975), requiring an accurate and robust description of the thermodynamics of near-critical CO2. Other issues for aquifer disposal include hydrodynamic instabilities (viscous, gravitational), interaction of $\mathrm{CO} 2$-water mixtures with heterogeneities on different scales, the kinetics of $\mathrm{CO} 2$ dissolution in saline aqueous fluids during unstable immiscible displacement, and chemical interactions between aqueous CO2-rich fluids and primary aquifer minerals. Non-isothermal effects may also come into play. There is much experience with storage of natural gas in aquifers which is relevant to the problem of CO2 disposal (Katz and Lee, 1990). Considerable work on flow processes in water-CO2 systems has been done in geothermal reservoir engineering (e.g., O’Sullivan et al., 1985; Battistelli et al., 1997; Xu and Pruess, 2000). In geothermal applications, temperatures are higher and $\mathrm{CO} 2$ pressures lower than would be expected in $\mathrm{CO} 2$ aquifer disposal systems.

For $\mathrm{CO} 2$ injection into natural gas fields, the important issues involve the degree of mixing, and hydrodynamic dispersion effects in single phase flow as $\mathrm{CO} 2$ displaces in situ gas. Enhanced oil recovery (EOR) using $\mathrm{CO} 2$ requires an understanding of the complex phase behavior of mixtures of $\mathrm{CO} 2$ and crude oil. There is much practical experience with using $\mathrm{CO} 2$ for EOR projects (SPE, 1999), and sophisticated numerical simulation capabilities are available (Chang et al., 
1994). Some numerical simulation capabilities are also available for coupled hydromechanical effects due to pressure buildup from $\mathrm{CO} 2$ injection, as well as for coupled hydrochemical effects due to interaction of $\mathrm{CO} 2$ with mineral assemblages. Both types of effects require rather sophisticated codes that handle couplings between physiochemical processes of different time constants and non-linearities. Some testing of these kinds of codes has been done in related problems (Jing et al., 1998; Xu and Pruess, 2000). There is some practical as well as modeling experience with using "cushion gas" to enhance the efficiency of aquifer gas storage (Modine and Bashbush, 1987). Although this employs gases other than CO2, the experience will be relevant to $\mathrm{CO} 2$ also. Practical experience with large-scale injection of $\mathrm{CO} 2$ in aquifers is limited to the single case of the Sleipner Vest field in the Norwegian sector of the North Sea (Korbol and Kaddour, 1995; Kongsjorden et al., 1997).

\section{APPROACH}

The present authors propose to organize and manage the model intercomparison study; facilitate the development and selection of appropriate test problems; distribute them to interested groups of scientists and engineers who want to participate in this exercise; and solicit, collect, reconcile, and document solutions. This report includes a first preliminary set of problems (see below) and is intended to initiate the study. It is being disseminated widely to groups worldwide that have relevant expertise and access to simulation tools for geologic sequestration of greenhouse gases. We encourage such groups to participate in the study through their own funding by making suggestions for enhancing (refining) problems and proposing additional ones, and by submitting solutions to existing simulation problems. All communication should proceed electronically by email to CO2sim@lbl.gov; for discussing issues related to specific test problems we encourage interested parties to communicate directly with the proposers of the test problems, whose e-mail addresses are given as footnotes to the problems. We have established a website (URL: http://esd.lbl.gov/GEOSEQ/) that will be used to document problem sets and post solutions and discussions. We plan to hold workshops at regular intervals to compare and discuss results and to refine problem definitions and develop new problems. Announcements will be posted on the web.

Development and selection of the sample problems to be used in the model intercomparison study will be made on the basis of key processes expected to occur in potential $\mathrm{CO} 2$ storage reservoirs, taking into account existing simulation capabilities and future needs. We anticipate that several problem sets will be developed to address the variety of issues encountered in the different potential disposal reservoirs. In addition, a phased approach will be used in which problems will proceed from simple to complex. The initial test problems emphasize PVT properties at thermodynamic conditions of interest, and the mechanics of the interaction of $\mathrm{CO} 2$ with native 
reservoir fluids in simplified systems. At a later stage simulation problems will be developed that address more complex and realistic systems, where mixtures of $\mathrm{CO} 2$ with other gases may be injected into heterogeneous reservoirs and may be subject to coupled chemical, mechanical, and thermal interactions with the host rocks.

Benchmark problems will not be limited to hypothetical modeling exercises, but will use to the extent possible the main features and parameters of real case histories or practical field projects currently underway. For example, experience and data from the Sleipner Vest case may be used to address fluid dynamics issues, while data on mineral assemblages in natural $\mathrm{CO} 2$ fields such as Bravo Dome, New Mexico, and Pisgah Anticline, Mississippi, may be used for chemical speciation and reaction path modeling (Studlick et al., 1990; Pearce et al., 1996).

\section{GUIDELINES FOR TEST PROBLEMS}

1. Problems should be practical and of wide interest and applicability.

2. Contributors of problems must affirm that they have actually solved the problem to some level of correctness.

3. Problem descriptions should follow the general outline below.

4. Among the various convenient units used in any given problem specification, there must also be specifications in MKS (SI).

5. The contributor of a problem will act as coordinator and referee to answer questions and assist in judging results.

6. If there is not sufficient interest in a problem, it will be placed in an inactive category where potential testers can view it for future inclusion in the active study.

\section{OUTLINE OF PROBLEM SPECIFICATIONS}

Problems should be described using the following headings:

1. Introduction and general description

2. List of processes being studied

3. Definition of the problem and input data

4. Problem variations

5. Definition of results to be calculated

6. Comparison criteria

7. References

The section on "problem variations" lists optional modifications that may make the problem more useful for an intercomparison study. In some cases these entail simplifications that remove features 
deemed nonessential; other variations enhance the scope of the problem by varying parameters or by introducing additional processes.

\section{PRELIMINARY PLAN AND SCHEDULE}

The preliminary plan and schedule are proposed as follows:

1) Initial problem sets (this report) - Month 0

2) Receiving responses, suggestions, input and proposals of test problems from interested groups - Month 2

3) Selection of first set of benchmark problems and emailing of problem specifications to interested groups - Month 3

4) Simulation studies by interested groups - Month 3-9

5) Working meeting to discuss results, refine problem definitions, develop new test problems, and agree on future plan and schedule - Month 10

\section{DESCRIPTIONS OF INITIAL TEST PROBLEMS}

An initial set of proposed test problems is attached to this report. The titles are as follows.

Test Problem 1. Mixing of Stably Stratified Gases

Test Problem 2. Advective-Diffusive Mixing Due to Lateral Density Gradient

Test Problem 3. Radial Flow from a CO2 Injection Well

Test Problem 4. CO2 Discharge Along a Fault Zone

Test Problem 5. Mineral Trapping in a Glauconitic Sandstone Aquifer

Test Problem 6. Hydromechanical Responses During CO2 Injection into an Aquifer-Caprock System

Test Problem 7. $\mathrm{CO}_{2}$ Injection into a 2-D Layered Brine Formation

Test Problem 8. $\mathrm{CO}_{2}$-Oil Displacement and Phase Behavior

Readers are encouraged to submit comments, suggestions, and solutions to us via e-mail at CO2sim@lbl.gov. We are also interested to obtain proposals for additional problems.

\section{ACKNOWLEDGEMENT}

For a review of the manuscript the authors are indebted to Sally Benson and Larry Myer. We thank Tianfu Xu, Jonny Rutqvist, Carl Steefel, and Tony Kovscek for contributing test problems. This work was supported by the National Energy Technology Laboratory (NETL) of the U.S. Department of Energy under Contract No. DE-AC03-76SF00098. 


\section{REFERENCES}

Battistelli, A., C. Calore and K. Pruess. The Simulator TOUGH2/EWASG for Modeling Geothermal Reservoirs with Brines and Non-Condensible Gas, Geothermics, Vol. 26, No. 4, pp. 437 - 464, 1997.

Chang, Y.B., M.T. Lim, G.A. Pope and K. Sepehrnoori. CO2 Flow Patterns Under Multiphase Flow: Heterogeneous Field-Scale Conditions, SPE Reservoir Engineering, pp. 208 - 216, 1994.

Chapman, N., J. Andersson, P. Bogorinski, J. Carrera, J. Hadermann, D. Hodgkinson, P. Jackson, I. Neretnieks, S. Neuman, K. Skagius, T. Nicolson, C.F. Tsang and C. Voss. Developing Groundwater Flow and Transport Models for Radioactive Waste Disposal - Six Years of Experience from the INTRAVAL Project, in the proceedings of an NEA/SKI Symposium, Paris, France, pp. 45 -58, October, 1994.

Jing L., O. Stephansson, C.-F. Tsang, L. Knight and F. Kautsky. DECOVALEX II - Project. Technical Report Task 1A and 1B. Swedish Nuclear Power Inspectorate, SKI Report 98:39, 1998.

Jing L., C. F. Tsang, and O. Stephansson, DECOVALEX: an International Co-operative Research Project on Mathematical Models of Coupled T-H-M Processes for Safety Analysis of Radioactive Waste Repositories. Int. J. Rock Mech. Min. Sci. \& Geomech. Abstr., Vol. 32, No. 5, pp. 389-398, 1995.

Katz, D.L. and R.L. Lee. Natural Gas Engineering, McGraw-Hill Publ. Comp., New York, NY 1990.

Firoozabadi, A. and L. K. Thomas. Sixth SPE Comparative Solution Project: A Comparison of Dual-Porosity Simulators, paper SPE-18741, presented at Tenth SPE Symposium on Reservoir SimulationHouston, Texas, February 6-8, 1989.

Kongsjorden, H., O. Karstad and T.A. Torp. Saline Aquifer Storage of Carbon Dioxide in the Sleipner Project, Waste Management, Vol. 17, No. 5/6, pp. 303 - 308, 1997.

Korbol, R. and A. Kaddour. Sleipner Vest CO2 Disposal - Injection of Removed CO2 into the Utsira Formation, Energy Convers. Mgmt., Vol. 36, No. 6 - 9, pp. 509 - 512, 1995.

Larsson, A. The International Projects INTRACOIN, HYDRAOCOIN, and INTRAVAL, short communication in Advances in Water Resources, Vol. 15, pp. 85 - 87, 1992.

Modine, A.D. and J.L. Bashbush. The Application of the Method of Characteristics to the Flow of Miscible Gases in a Reservoir, paper SPE - 16988, presented at the 62nd Annual Technical Conference and Exhibition of the Society of Petroleum Engineers, Dallas, TX, 1987.

O'Sullivan, M.J., G.S. Bodvarsson, K. Pruess and M.R. Blakeley. Fluid and Heat Flow in Gasrich Geothermal Reservoirs, Soc. Pet. Eng. J., 25 (2), 215-226, 1985.

Pearce, J.M. S. Holloway, H. Wacker, M.K. Nelis, C. Rochelle and K. Bateman. Natural Occurrences as Analogues for the Geological Disposal of Carbon Dioxide. Energy Convers. Mgmt., Vol. 37(6-8), pp. 1123 - 1128, 1996.

SPE (ed.), CO2 Flooding, Reprint Series No. 51, Society of Petroleum Engineers, Richardson, TX, 1999. 
Stanford Geothermal Program (ed.). Proceedings of the Special Panel on Geothermal Model Intercomparison Study. Report: SGP-TR42. Also presented at: 6th Workshop on Geothermal Reservoir Engineering, Stanford University, Stanford, California, 16-18 December, 1980.

Stephansson, O., L. Jing, and C.-F. Tsang (editors), Mathematical and Experimental Studies of Coupled Thermo-Hydro-Mechanical Processes in Fractured Media-DECOVALEX, Developments in Geotechnical Engineering Series, Number 79. Elsevier Science Publishers, December 1996.

Studlick, J.R.J., R.D.Shew, G.L. Basye and J.R. Ray. A Giant Carbon Dioxide Accumulation in the Norphlet Formation, Pisgah Anticline, Mississipi, in J.H. Barwis, J.G. McPherson and J.R.J. Studlick (eds.), Sandstone Petroleum Reservoirs, Springer Verlag, New York., pp. 181203, 1990.

Vargaftik, N.B. Tables on the Thermophysical Properties of Liquids and Gases, 2nd Ed., John Wiley \& Sons, New York, NY, 1975.

$\mathrm{Xu}, \mathrm{T}$. and K. Pruess. On Fluid Flow and Mineral Alteration in Fractured Caprock of Magmatic Hydrothermal Systems, J. Geophys. Res., in press, 2000. 


\section{Test Problem 1. Mixing of Stably Stratified Gases"}

\section{INTRODUCTION AND GENERAL DESCRIPTION}

In this problem, $\mathrm{CO} 2$ and $\mathrm{CH} 4$ gases are placed in contact one on top of the other and allowed to mix as controlled by diffusion and associated flow at 40 bars, $40{ }^{\circ} \mathrm{C}$. Mixing in the system is limited because the denser gas (CO2) is on the bottom and the lighter gas ( $\mathrm{CH} 4)$ is on the top. The diffusion and flow are assumed to be one-dimensional. A residual liquid water saturation of 0.1 exists within the pores.

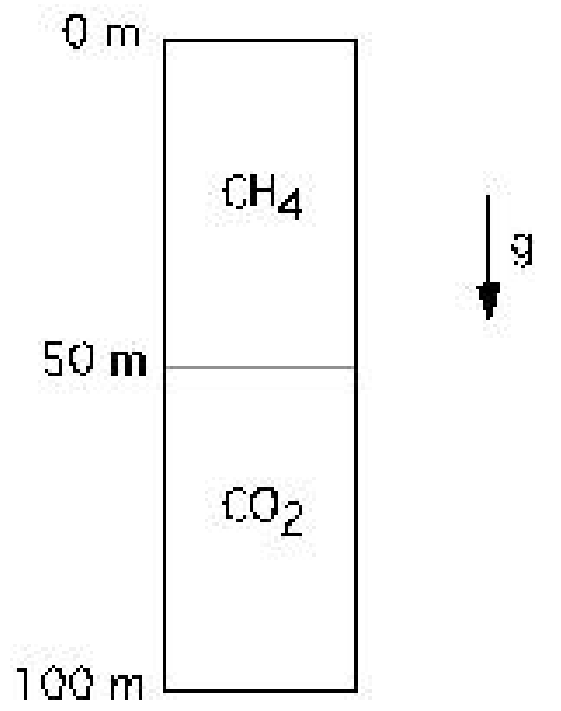

\section{LIST OF PROCESSES BEING STUDIED}

Molecular diffusion.

Density, viscosity, and solubility formulations of water, $\mathrm{CO} 2$, and $\mathrm{CH} 4$ as functions of pressure, temperature, and composition ( $\mathrm{P}, \mathrm{T}, \mathrm{X})$.

Advection in response to pressure gradients induced by equimolar diffusion of species with different molecular weights.

\section{DEFINITION OF THE PROBLEM AND INPUT DATA}

\section{Boundary conditions:}

No heat or mass flux through any boundaries (i.e., all boundaries are no-flow).

\section{Initial conditions:}

$\mathrm{T}=40{ }^{\circ} \mathrm{C}$ (isothermal throughout)

\# proposed by Curt Oldenburg; e-mail: CMOldenburg@1bl.gov 
$\mathrm{P}(\mathrm{Z}=0 \mathrm{~m})=40$ bars

$\mathrm{X}$ initially stratified with $\mathrm{CO} 2$ occupying the bottom half of the domain and $\mathrm{CH} 4$ occupying the top half.

\section{Input data:}

a) Porosity, tortuosity, residual liquid saturation (0.1, 1., 0.1 , respectively)

b) Molecular diffusivity $\left(1 \times 10^{-7} \mathrm{~m}^{2} \mathrm{~s}^{-1}\right)$

c) Permeability and relative permeability $\left(\mathrm{k}=10^{-14} \mathrm{~m}^{2}\right.$, linear $\mathrm{k}_{\mathrm{rg}}$, liquid immobile)

d) Density, viscosity, and solubility in water of $\mathrm{CO} 2$ and $\mathrm{CH} 4$ as functions of $\mathrm{P}, \mathrm{T}$, and $\mathrm{X}$.

e) Vapor-liquid equilibrium properties of water.

\section{PROBLEM VARIATIONS}

a) Diffusion only with no gas-phase flow.

b) Low pressure scenario ( $\mathrm{P}=1$ bar).

c) High pressure scenario $(\mathrm{P}=100 \mathrm{bar})$

d) Mixing by Dusty Gas Model instead of advective-diffusive Fickian model.

\section{DEFINITION OF RESULTS TO BE CALCULATED}

Vertical profiles at various times of :

a) $\mathrm{CO} 2$ and $\mathrm{CH} 4$ masses in liquid and gas phases per unit volume.

b) Pressure.

c) Density of the gas mixture.

\section{COMPARISON CRITERIA}

Profiles at the same times should match within $5 \%$.

\section{REFERENCES}

Severinghaus, J.P., M.L. Bender, R.F. Keeling, and W.S. Broecker, Fractionation of soil gases by diffusion of water vapor, gravitational settling, and thermal diffusion, Geochimica et Cosmochimica Acta, 60(6), 1005-1018, 1996.

Thorstenson, D.C. and D.W. Pollock, Gas transport in unsaturated zones: Multicomponent systems and the adequacy of Fick's Laws, Water Resour. Res., 25(3), 477-507, 1989. 


\section{Test Problem 2. Advective-Diffusive Mixing Due to Lateral Density Gradient"}

\section{INTRODUCTION AND GENERAL DESCRIPTION}

In this problem, $\mathrm{CO} 2$ and $\mathrm{CH} 4$ gases are placed side-by-side in a container and allowed to mix by advection and diffusion. The strong lateral density gradient between the dense $\mathrm{CO} 2$ gas and the relatively light $\mathrm{CH} 4$ gas causes a strong flow where $\mathrm{CO} 2$ tends to move downward and $\mathrm{CH} 4$ tends to move upward to the top of the container. The flow and diffusion are assumed to be twodimensional. A residual liquid water saturation of 0.1 exists within the pores.

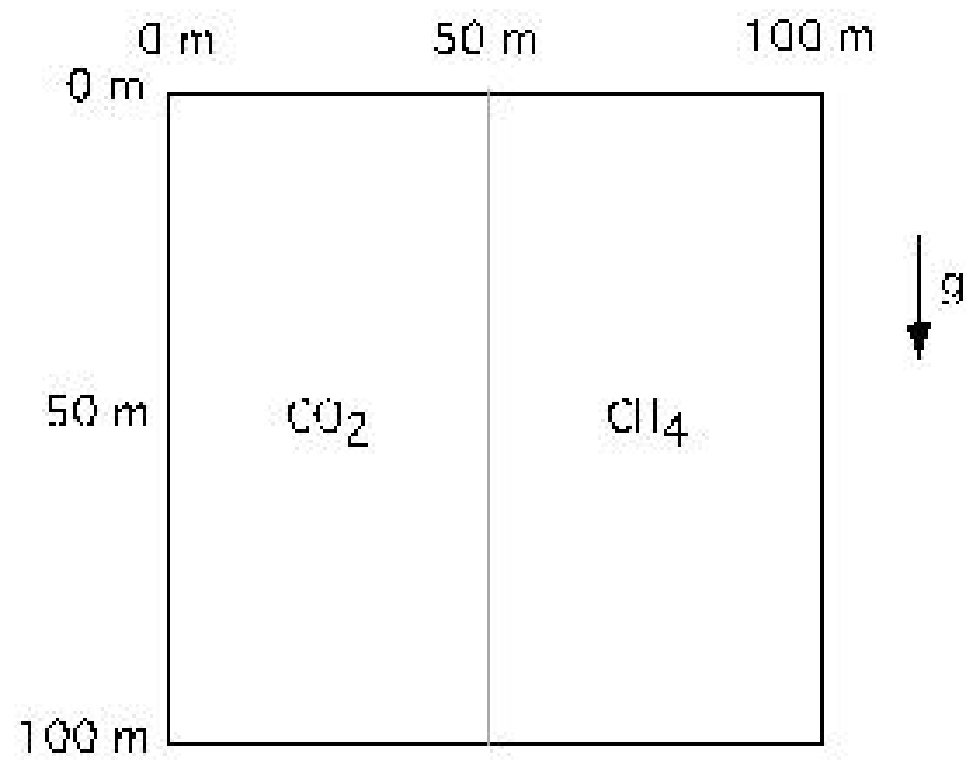

\section{LIST OF PROCESSES BEING STUDIED}

Gravity-driven advection in response to strong lateral density gradient.

Molecular diffusion.

Density, viscosity, and solubility formulations as functions of pressure, temperature, and composition (P, T, X).

Because of the strong advection, numerical dispersion will arise for most numerical methods.

\section{DEFINITION OF THE PROBLEM AND INPUT DATA}

Boundary conditions:

No heat or mass flux through any boundaries (i.e., all boundaries are no-flow).

\# proposed by Curt Oldenburg; e-mail: CMOldenburg@lbl.gov 
Initial conditions:

$\mathrm{T}=40{ }^{\circ} \mathrm{C}$ (isothermal throughout)

$\mathrm{P}(\mathrm{Z}=0 \mathrm{~m})=40$ bars

Initial composition field with $\mathrm{CO} 2$ on the left-hand half of the domain and $\mathrm{CH} 4$ on the right-hand half of the domain.

\section{Input data:}

a) Porosity, tortuosity, liquid saturation $(0.1,1 ., 0.1$, respectively)

b) Molecular diffusivity $\left(1 \times 10^{-7} \mathrm{~m}^{2} \mathrm{~s}^{-1}\right)$

c) Permeability and relative permeability $\left(\mathrm{k}=10^{-14} \mathrm{~m}^{2}\right.$, linear $\mathrm{k}_{\mathrm{rg}}$, liquid immobile)

d) Density, viscosity, and solubility in water of $\mathrm{CO} 2$ and $\mathrm{CH} 4$ as functions of $\mathrm{P}, \mathrm{T}$, and $\mathrm{X}$.

e) Vapor-liquid equilibrium properties of water.

\section{PROBLEM VARIATIONS}

a) Low pressure scenario ( $\mathrm{P}=1 \mathrm{bar})$.

b) High pressure scenario $(\mathrm{P}=100 \mathrm{bar})$.

c) Mixing by Dusty Gas Model instead of advective-diffusive Fickian model.

d) Substitute nitrogen (N2) or air for CO2.

\section{DEFINITION OF RESULTS TO BE CALCULATED}

Horizontal profiles at $\mathrm{Z}=50 \mathrm{~m}$ at various times of

a) $\mathrm{CO} 2$ and $\mathrm{CH} 4$ masses in gas and liquid phases per unit volume.

b) Density of the gas mixture.

\section{COMPARISON CRITERIA}

Profiles at the same times should match within $5 \%$.

\section{REFERENCES}

To be supplied. 


\section{Test Problem 3. Radial Flow from a CO2 Injection Well\&}

\section{INTRODUCTION AND GENERAL DESCRIPTION}

This problem addresses two-phase flow of $\mathrm{CO} 2$ and water for simplified flow geometry and medium properties. The aquifer into which injection is made is assumed infinite-acting, homogenoeus, and isotropic. Gravity and inertial effects are neglected, injection is made at a constant mass rate, and flow is assumed 1-D radial (line source). Under the conditions stated the problem has a similarity solution where dependence on radial distance $\mathrm{R}$ and time t occurs only through the similarity variable $\xi=\mathrm{R}^{2 / t}$ (O'Sullivan 1981; Doughty and Pruess 1992).

\section{LIST OF PROCESSES BEING STUDIED}

Two-phase flow of $\mathrm{CO} 2$ and water subject to relative permeability and capillary effects.

Change of fluid density, viscosity, and $\mathrm{CO} 2$ solubility with pressure and salinity.

Formation dry-out with precipitation of salt.

\section{DEFINITION OF THE PROBLEM AND INPUT DATA}

Problem parameters are summarized in Tables 3.1 and 3.2

\section{PROBLEM VARIATIONS}

Neglect salinity of the aqueous phase. Include non-isothermal effects. Include permeability changes due to precipitation. Inject gas that is $50 \% \mathrm{CO} 2,50 \% \mathrm{~N} 2$.

\section{DEFINITION OF RESULTS TO BE CALCULATED}

Data on $\mathrm{CO} 2$ and brine density and viscosity, and $\mathrm{CO} 2$ solubility, for the range of thermodynamic conditions encountered in the problem. Gas saturation, dissolved CO2 mass fraction, fraction of void space containing precipitated salt, and fluid pressure as functions of the similarity variable $\xi=$ $\mathrm{R}^{2} / \mathrm{t}$. (Use both profiles at constant time and time-series data at a specific location for plotting.)

\section{COMPARISON CRITERIA}

Results should match within $+/-5 \%$.

\section{REFERENCES}

Corey, A.T. The Interrelation Between Gas and Oil Relative Permeabilities, Producers Monthly, pp. 38 - 41, November 1954.

\footnotetext{
\& proposed by Karsten Pruess; e-mail: K_Pruess@ @ lbl.gov
} 
Doughty, C. and K. Pruess. A Similarity Solution for Two-Phase Water, Air and Heat Flow Near a Linear Heat Source in a Porous Medium, J. of Geophys. Res., 97 (B2), 1821-1838, 1992.

O’Sullivan, M.J. A Similarity Method for Geothermal Well Test Analysis, Water Resour. Res., Vol. 17, No. 2, pp. $390-398,1981$.

van Genuchten, M.Th. A Closed-Form Equation for Predicting the Hydraulic Conductivity of Unsaturated Soils, Soil Sci. Soc. Am. J., Vol. 44, pp. 892 - 898, 1980.

Table 3.1 Hydrogeologic parameters.

\begin{tabular}{|l|l|}
\hline Permeability & $\mathrm{k}=10^{-13} \mathrm{~m}^{2}$ \\
Porosity & $\phi=0.12$ \\
Pore compressibility & $\mathrm{c}=4.5 \times 10^{-10} \mathrm{~Pa}^{-1}$ \\
Aquifer thickness & $100 \mathrm{~m}$
\end{tabular}

Table 3.2 Initial conditions and injection specifications

\begin{tabular}{|l|l|}
\hline Pressure & $120 \mathrm{bar}$ \\
\hline Temperature & $45{ }^{\circ} \mathrm{C}$ \\
\hline Salinity & $15 \mathrm{wt} .-\% \mathrm{NaCl}$ \\
\hline $\mathrm{CO} 2$ injection rate & $100 \mathrm{~kg} / \mathrm{s}$ \\
\hline
\end{tabular}




\section{Test Problem 4. CO2 Discharge Along a Fault Zone ${ }^{\&}$}

\section{INTRODUCTION AND GENERAL DESCRIPTION}

This problem explores $\mathrm{CO} 2$ loss from storage through a leaky fault, using a highly simplified 1-D linear flow geometry. It is envisioned that an aquifer into which $\mathrm{CO} 2$ disposal is made is intersected by a vertical fault, which establishes a connection through an otherwise impermeable caprock to another aquifer $500 \mathrm{~m}$ above the storage aquifer (Fig. 4.1a). This situation is idealized by assuming 1-D flow geometry and constant pressure boundary conditions as shown in Fig. 4.1b (Pruess and García, 2000).

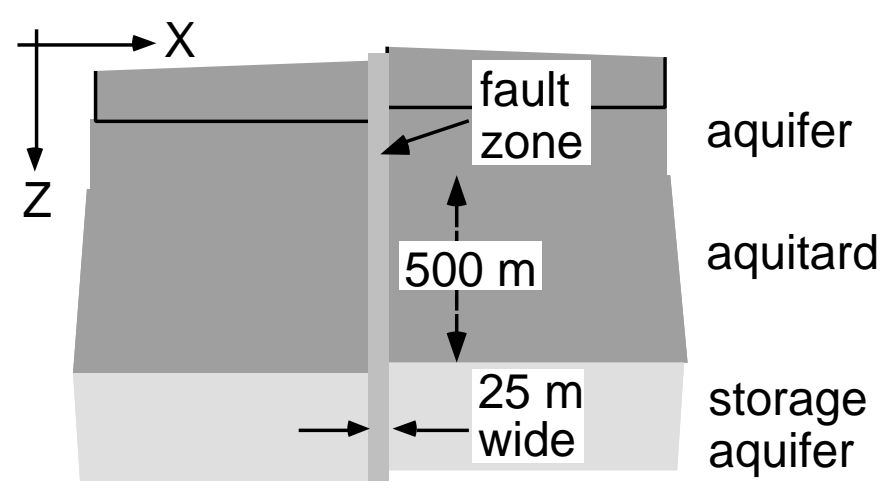

(a)

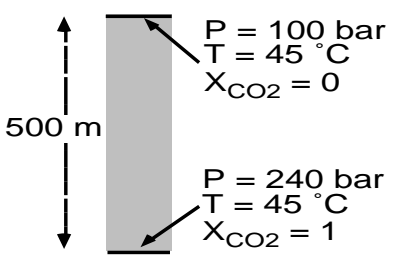

(b)

Figure 4.1 Schematic of the fault zone model (a) and applied boundary conditions (b).

\section{LIST OF PROCESSES BEING STUDIED}

Immiscible displacement of water by $\mathrm{CO} 2$ subject to pressure, gravity, and capillary pressure effects.

Change of fluid density, viscosity, and $\mathrm{CO} 2$ solubility with pressure.

Formation dry-out.

\section{DEFINITION OF THE PROBLEM AND INPUT DATA}

Hydrogeologic parameters are identical to those of problem 3 (Table 3.1), except that porosity is increased to $35 \%$. The fault zone is assumed to be $25 \mathrm{~m}$ wide and $500 \mathrm{~m}$ tall, with boundary conditions as given in Fig. 4.1b. The reservoir fluid is assumed to be pure water (no salinity). Initial conditions are pressures in hydrostatic equilibrium relative to $\mathrm{P}=100 \mathrm{bar}$ at the top; temperature is held constant at $\mathrm{T}=45^{\circ} \mathrm{C}$ throughout.

\& proposed by Karsten Pruess; e-mail: K_Pruess@lbl.gov 


\section{PROBLEM VARIATIONS}

Include salinity of the aqueous phase and permeability changes due to precipitation. Include nonisothermal effects. Assume gas composition is $50 \% \mathrm{CO} 2,50 \% \mathrm{~N} 2$.

\section{DEFINITION OF RESULTS TO BE CALCULATED}

Data on $\mathrm{CO} 2$ and water density and viscosity, and $\mathrm{CO} 2$ solubility, for the range of thermodynamic conditions encountered in the problem. Vertical profiles of gas saturation, fluid pressure, and dissolved $\mathrm{CO} 2$ mass fraction at different times. $\mathrm{CO} 2$ inventory in gas and liquid phases after $10^{7}$ seconds. Mass flow rates of $\mathrm{CO} 2$ at the bottom and of water at the top vs. time (normalized for a 1 $\mathrm{m}$ thick section).

\section{COMPARISON CRITERIA}

Results should match to with $+/-5 \%$.

\section{REFERENCES}

Pruess, K. and J. García. Multiphase Flow Dynamics During CO2 Injection into Saline Aquifers, submitted to Environmental Geology, September 2000. 


\section{Test Problem 5. Mineral Trapping in a Glauconitic Sandstone Aquifer*}

\section{INTRODUCTION AND GENERAL DESCRIPTION}

This problem addresses geochemical effects of $\mathrm{CO} 2$ injection into a glauconitic sandstone aquifer, and analyzes the impact of $\mathrm{CO} 2$ immobilization through carbonate precipitation. Batch reaction modeling of the geochemical evolution of this aquifer is performed in the presence of $\mathrm{CO} 2$ at high pressure. The problem is based on Gunter et al. (1997), who modeled water-rock reactions when $\mathrm{CO} 2$ is injected into a glauconitic sandstone aquifer in the Alberta Sedimentary Basin, Canada. Additional processes are considered such as presence of organic matter and its oxidation.

\section{LIST OF PROCESSES BEING STUDIED}

The following processes are considered: (1) equilibrium aqueous complexation, (2) redox processes, (3) the kinetics of chemical interactions between the host rock minerals and the aqueous phase (organic matter dissolution is a non-equilibrium processes), and (4) $\mathrm{CO} 2$ solubility dependence on pressure, temperature and salinity of the system. In addition, changes in porosity are monitored during the simulations.

\section{DEFINITION OF THE PROBLEM AND INPUT DATA}

The initial condition used in the simulation is a pure $1.0 \mathrm{M}$ solution of sodium chloride reacting with the primary minerals listed in Table 5.1 at a temperature of $54{ }^{\circ} \mathrm{C}$, a pH of 7 , and an Eh of -0.1 V. Reactant phases are those minerals initially present in the aquifer formation (Table 5.1). The reactant minerals dissolve progressively into the formation water, thus modifying the water composition and leading to precipitation of product phases. Two simulations are to be performed with the same initial conditions. The first simulation examines water-rock interaction under natural conditions without $\mathrm{CO} 2$ injection. The second simulation considers a $\mathrm{CO} 2$ injection pressure of 260 bar. The $\mathrm{CO} 2$ gas pressure is assumed to be maintained in equilibrium with the solution at all times. A simulation time of 100,000 years is used for both simulations.

The rate law for kinetic mineral dissolution and precipitation is taken from Lasaga (1984) and Steefel and Lasaga (1994):

$$
\mathrm{r}_{\mathrm{m}}=\mathrm{A}_{\mathrm{m} k \mathrm{~m}}\left[1-\left(\frac{\mathrm{Q}_{\mathrm{m}}}{\mathrm{K}_{\mathrm{m}}}\right)^{\mu}\right]^{\mathrm{n}}
$$

\footnotetext{
* proposed by Tianfu Xu; e-mail: Tianfu_Xu@lbl.gov
} 
where $\mathrm{m}$ is mineral index, $\mathrm{r}_{\mathrm{m}}$ is the dissolution/precipitation rate (positive values indicate dissolution, and negative values precipitation), $\mathrm{A}_{\mathrm{m}}$ is the specific reactive surface area per $\mathrm{kg} \mathrm{H}_{2} \mathrm{O}$, $\mathrm{k}_{\mathrm{m}}$ is the rate constant (moles per unit mineral surface area and unit time) which is temperature dependent, $\mathrm{K}_{\mathrm{m}}$ is the equilibrium constant for the mineral-water reaction written for the destruction of one mole of mineral $\mathrm{m}$, and $\mathrm{Q}_{\mathrm{m}}$ is the ion activity product. The parameters $\mu$ and $\mathrm{n}$ are taken equal to unity. Rate constant dependency as a function of temperature is

$$
\mathrm{k}=\mathrm{k}_{25} \exp \left[\frac{-\mathrm{E}_{\mathrm{a}}}{\mathrm{R}}\left(\frac{1}{\mathrm{~T}}-\frac{1}{298.15}\right)\right]
$$

where $\mathrm{E}_{\mathrm{a}}$ is the activation energy, $\mathrm{k}_{25}$ is the rate constant at $25^{\circ} \mathrm{C}, \mathrm{R}$ is gas constant, $\mathrm{T}$ is absolute temperature. The kinetic parameters are also given in Table 5.1. Precipitation of possible secondary minerals (Table 5.1 with initial $\mathrm{V}_{\mathrm{f}}=0$ where $\mathrm{V}_{\mathrm{f}}$ is mineral volume fraction) is represented using the same kinetic rate expression as that for dissolution. The precipitation kinetic constant for a secondary mineral is assumed to be one order of magnitude greater than its corresponding dissolution rate constant. A total surface area of $10 \mathrm{~m}^{2} / \mathrm{dm}^{3}$ medium was used. The initial surface area of each primary mineral is calculated by multiplying its volume fraction with the total surface area (Table 5.1). With time, the surface areas change in complex ways. We simply relate the surface areas of the primary minerals at some time to the mineral volume fraction by

$$
A=A^{0} \frac{V_{f}}{V_{f}^{0}}
$$

where $A$ and $V_{f}$ are the reactive surface area and volume fraction of a primary mineral, respectively, and superscript zero indicates the values at time $\mathrm{t}=0$. The reactive surface areas for secondary minerals are set to $0.25 \mathrm{~m}^{2} / \mathrm{dm}^{3}$ at all times.

\section{PROBLEM VARIATIONS}

Neglect $\mathrm{CO} 2$ solubility dependence on pressure, temperature and salinity. The reactive surface areas used for both primary and secondary minerals are uncertain and may be varied. The results also vary with thermodynamic and kinetic data.

\section{DEFINITION OF RESULTS TO BE CALCULATED}

The following variables are reported vs. time, (1) aqueous species concentrations, (2) $\mathrm{pH}$ and Eh, (3) changes of volume fraction of both primary and secondary minerals, (4) change of porosity, (5) the amounts of $\mathrm{CO} 2$ trapped in both liquid and solid phases. 
Table 5.1. List of initial mineral volume fractions, potential secondary mineral phases, and their kinetic properties. All rate constants are listed for dissolution. The constants for precipitation are increased correspondingly by one order of magnitude.

\begin{tabular}{|c|c|c|c|c|c|c|}
\hline Mineral & Chemical composition & $\begin{array}{l}\text { Volume } \\
(\%)\end{array}$ & $\begin{array}{l}\text { Surface } \\
\text { area } \\
\left(\mathrm{m}^{2} / \mathrm{dm}^{3}\right. \\
\text { medium })\end{array}$ & $\begin{array}{l}\mathrm{k}_{25} \\
\left(\mathrm{moles} / \mathrm{m}^{2} \mathrm{~s}\right)\end{array}$ & $\begin{array}{l}\mathrm{E}_{\mathrm{a}} \\
(\mathrm{kJ} / \mathrm{mol})\end{array}$ & Reference \\
\hline \multicolumn{7}{|l|}{ Primary: } \\
\hline quartz & $\mathrm{SiO}_{2}$ & 71.28 & 7.128 & $1.2589 \times 10^{-14}$ & 87.50 & Tester et al. (1994) \\
\hline K-feldspar & $\mathrm{KAlSi}_{3} \mathrm{O}_{8}$ & 1.76 & 0.176 & $1.00 \times 10^{-12}$ & 67.83 & Blum and Stillings (1995) \\
\hline kaolinite & $\mathrm{Al}_{2} \mathrm{Si}_{2} \mathrm{O}_{5}(\mathrm{OH})_{4}$ & 1.76 & $0.176 \mathrm{E} 2$ & $1.00 \times 10^{-13}$ & 62.76 & Nagy (1995) \\
\hline calcite & $\mathrm{CaCO}_{3}$ & 0.88 & 0.088 & $1.60 \times 10^{-9}$ & 41.87 & Svensson and Dreybrodt (1992) \\
\hline dolomite & $\mathrm{CaMg}\left(\mathrm{CO}_{3}\right)_{2}$ & 0.88 & 0.088 & $0.60 \times 10^{-9}$ & 41.87 & assigned based on calcite \\
\hline siderite & $\mathrm{FeCO}_{3}$ & 0.88 & 0.088 & $0.60 \times 10^{-9}$ & 41.87 & assigned based on calcite \\
\hline illite & $\mathrm{K}_{0.6} \mathrm{Mg}_{0.25} \mathrm{Al}_{1.8}\left(\mathrm{Al}_{0.5} \mathrm{Si}_{3.5} \mathrm{O}_{10}\right)(\mathrm{OH})$ & 2.64 & $0.264 \mathrm{E} 2$ & $1.00 \times 10^{-14}$ & 58.62 & Knauss and Wolery (1989) \\
\hline glauconite & 2 & 4.4 & $0.440 \mathrm{E} 1$ & $1.00 \times 10^{-14}$ & 58.62 & set to illite \\
\hline organic & $\mathrm{K}_{1.5} \mathrm{Mg}_{0.5} \mathrm{Fe}_{2.5} \mathrm{Fe}_{0.5} \mathrm{AlSi}_{7.5} \mathrm{O}_{20}(\mathrm{OH})_{2}$ & 2.64 & 0.264 & $1.00 \times 10^{-13}$ & 0.0 & assigned based on kaolinite \\
\hline oligoclase & $\mathrm{CH}_{2} \mathrm{O}$ & 0.88 & 0.088 & $1.00 \times 10^{-12}$ & 67.83 & set to K-feldspar \\
\hline porosity & $\mathrm{CaNa}_{4} \mathrm{Al}_{6} \mathrm{Si}_{14} \mathrm{O}_{40}$ & 12 & & & & \\
\hline total & ------ & 100 & & & & \\
\hline \multicolumn{7}{|l|}{ Secondary: } \\
\hline albite-low & & 0.0 & 0.25 & $1.00 \times 10^{-12}$ & 67.83 & Blum and Stillings (1995) \\
\hline smectite- $\mathrm{Na}$ & $\mathrm{NaAlSi}_{3} \mathrm{O}_{8}$ & 0.0 & $0.25 \mathrm{E} 2$ & $1.00 \times 10^{-14}$ & 58.62 & set to illite \\
\hline smectite-Ca & $\begin{array}{l}\mathrm{Na}_{0.29} \mathrm{Mg}_{0.26} \mathrm{Al}_{1.77} \mathrm{Si}_{3.97} \mathrm{O}_{10}(\mathrm{OH})_{2} \\
\mathrm{Ca}_{0.145} \mathrm{Mg}_{0.26} \mathrm{Al}_{1.77} \mathrm{Si}_{3.97} \mathrm{O}_{10}(\mathrm{OH})_{2}\end{array}$ & 0.0 & $0.25 \mathrm{E} 2$ & $1.00 \times 10^{-14}$ & 58.62 & set to illite \\
\hline
\end{tabular}

\section{COMPARISON CRITERIA}

Results should match within $+/-5 \%$.

\section{REFERENCES}

Blum, A. E., and Stillings, L. L., 1995, Feldspar dissolution kinetics, Chapter 7 of chemical weathering rates of silicate minerals, White, A.F., and Brantley, S. L. (eds), Mineral Society of America, v. 31, p. 291-351, Washington D. C.

Gunter W. D., Wiwchar, B., and Perkins, E. H., 1997, Aquifer disposal of CO2-rich greenhouse gases: extension of the time scale of experiment for $\mathrm{CO}_{2}$-sequestering reactions by geochemical modeling, Mineral. and Petrol., V. 59, p. 121-140.

Knauss, K. G., and Wolery, T. J., 1989, Muscovite dissolution kinetics as a function of $\mathrm{pH}$ and time at $70^{\circ}$ C." Geochimica et Cosmochimica Acta, V. 53, p. 1493-1501.

Lasaga, A. C., 1984, Chemical kinetics of water-rock interactions, Journal of Geophysical Research, v. 89, p. 4009-4025.

Nagy, K. L., Dissolution and precipitation kinetics of sheet silicates, 1995, Chemical Weathering Rates of Silicate Minerals, V. 31, p. 291-351. 
Rudnicki, J. I., and Wawersik, W. R., 1999, Report looks at sequestrating CO2 beneath earth's surface, EOS, Transactions of American Geophysical Union, v. 80, No. 50, p. 607-608.

Steefel, C. I., and Lasaga, A. C., 1994, A coupled model for transport of multiple chemical species and kinetic precipitation/dissolution reactions with applications to reactive flow in single phase hydrothermal system, American Journal of Science, v. 294, p. 529-592.

Svensson, U. and Dreybrodt, W., 1992. Dissolution kinetics of natural calcite minerals in CO2water systems approaching calcite equilibrium." Chemical Geology, v. 100, p. 129-145. Amsterdam, The Netherlands, Elsevier Science Publishers.

Tester, J. W., Worley, G. W., Robinson, B. A., Grigsby, C. O., and Feerer, J. L., 1994, Correlating quartz dissolution kinetics in pure water from 25 to $625^{\circ} \mathrm{C}$., Geochimica et Cosmochimica Acta, v. 58, p. 2407-2420. 


\section{Test Problem 6. Hydromechanical Responses During CO2 Injection into an Aquifer- Caprock System \%}

\section{INTRODUCTION AND GENERAL DESCRIPTION}

This problem addresses consequences of rock deformation, including potential change in permeability and porosity, during injection of $\mathrm{CO} 2$ into a porous aquifer beneath a low permeable caprock. The problem is simplified to a one-dimensional vertical column of an aquifer-caprock system (Figure 6.1). The injection is conducted at 1500 meters depth at a pre-determined constant pressure. The hydraulic boundary conditions are "no flow" except at the ground surface. As a consequence, the injected gas can only escape the aquifer through the low-permeability caprock. Because the permeability of the caprock is assumed to be stress dependent, the leakage rate will be affected by induced effective stress changes during the $\mathrm{CO} 2$ injection. The test problem is designed to induce substantial porosity and permeability change to emphasize the coupled hydromechanical effects in the code comparison.

\section{LIST OF PROCESSES BEING STUDIED}

The following processes are considered: (1) injection of $\mathrm{CO} 2$ gas into a fully water saturated aquifer with migration of gas upwards in the vertical column through a low permeability caprock; (2) mechanical stress changes and deformation in the aquifer and caprock as a consequence of changes in pore pressure during injection of $\mathrm{CO} 2$ into the aquifer; and (3) changes in porosity and permeability caused by effective stress changes in both the aquifer and caprock. These processes do not induce any significant temperature changes and the simulation could therefore be conducted in isothermal mode. However, the effects of temperature on thermophysial properties of water and $\mathrm{CO} 2$ should be taken into account.

Changes in the capillary pressure function with changes in porosity can be neglected. We also neglect effects of chemical reactions with minerals and dissolution of $\mathrm{CO} 2$ in water.

\section{DEFINITION OF THE PROBLEM AND INPUT DATA}

The calculation should be done in two phases. First the pre-injection steady state conditions of stress, fluid pressure and temperature should be established. Thereafter, the actual injection simulation should be conducted.

Initial conditions of static equilibrium should be established in a steady state pre-injection calculation as follows.

\footnotetext{
$\%$ proposed by Chin-Fu Tsang and Jonny Rutqvist; e-mail: CFTsang@lbl.gov
} 
a) Initial isotropic stress field increasing with depth based on the weight of the overlying rock (bulk density $=2260 \mathrm{~kg} / \mathrm{m}^{3}$ and acceleration of gravity $=9.81 \mathrm{~m} / \mathrm{s}^{2}$ )

b) Initial fully saturated rock with a hydrostatic gradient calculated assuming a liquid pressure of $\mathrm{P}_{1}=0.1 \mathrm{MPa}$ at the ground surface. Standard functions for water density (with temperature dependency) should be used.

c) An initial temperature with a thermal gradient of $30^{\circ} \mathrm{C} / \mathrm{km}$ (assume fixed temperatures of 10 ${ }^{\circ} \mathrm{C}$ at the ground surface and $55^{\circ} \mathrm{C}$ at 1500 meter depth).

d) An initial porosity and permeability distribution which are dependent on the mean effective stress according to equations in Table 6.1. That is, the initial porosity and permeability are decreasing with depth.

After achieving the steady state initial conditions, the injection operation should be simulated by injecting pure $\mathrm{CO} 2$ at 1500 meter depth (at the lower boundary of the model). The injection pressure should be kept constant at $30 \mathrm{MPa}$ (about $90 \%$ of the lithostatic pressure at 1500 meter depth) over a time period of 30 years.

Boundary conditions during the injection period:

a) Mechanical boundary conditions are locked for normal displacements (roller boundaries) on all boundaries except at the ground surface, which is free to move.

b) Gas pressure is kept constant (30 MPa) at the base of the model and the liquid pressure is kept constant at the ground surface $(0.1 \mathrm{MPa})$.

c) Temperature is kept constant $\left(55^{\circ} \mathrm{C}\right)$ at the base of the model and at the ground surface $(10$ $\left.{ }^{\circ} \mathrm{C}\right)$.

The problem domain includes two materials:

1) a low-permeability caprock, which extends from 1200 to $1300 \mathrm{~m}$ depth;

2) a rock mass with aquifer properties above and below the caprock.

Both materials are assumed linear elastic, with functions of porosity-stress, permeability-porosity, relative permeability and capillary pressure given in Table 6.1 .

\section{PROBLEM VARIATIONS}

Include additional processes such as dissolution of $\mathrm{CO} 2$ in the aqueous phase and changes of capillary pressure function with changes in porosity. Consider a two-dimensional model geometry with a vertical fault in the caprock. 


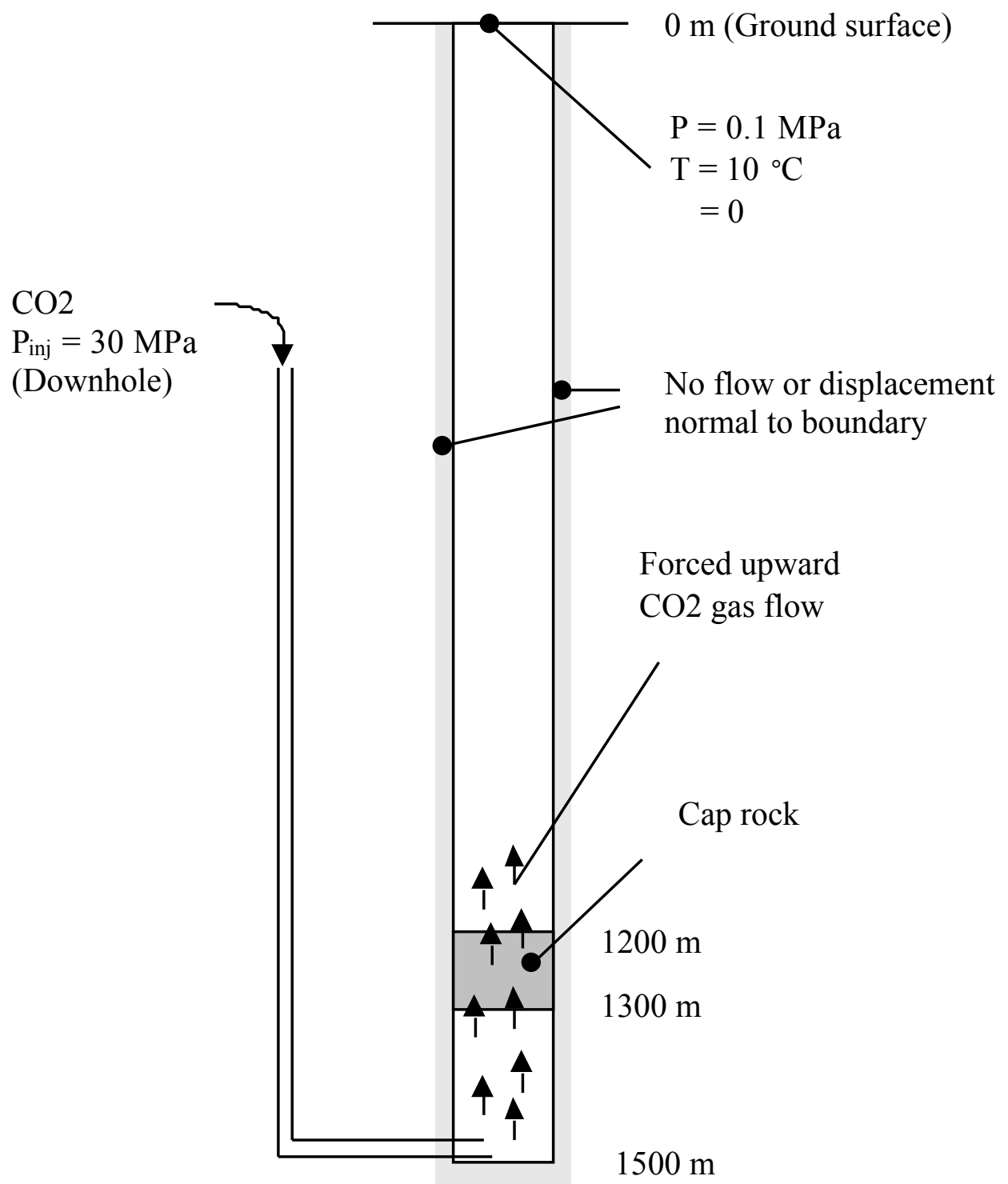

Figure 6.1. Geometry of vertical column for hydromechanical test problem.

\section{DEFINITION OF RESULTS TO BE CALCULATED}

The simulation of the injection period (30 years) should be conducted with and without consideration of permeability and porosity changes.

For both simulations, provide vertical profiles at various times of:

a) Gas saturation

b) Total CO2 mass

c) Fluid pressure 
Table 6.1. Rock properties.

\begin{tabular}{|c|c|c|}
\hline Rock Property & Aquifer & Caprock \\
\hline Young's modulus & $E=1.0 \mathrm{GPa}$ & $E=1.0 \mathrm{GPa}$ \\
\hline Poisson's ratio & $=0.25$ & $=0.25$ \\
\hline Saturated rock density & $=2260 \mathrm{~kg} / \mathrm{m}^{3}$ & $=2260 \mathrm{~kg} / \mathrm{m}^{3}$ \\
\hline $\begin{array}{l}\text { Porosity-stress function } \\
\text { Zero stress porosity } \\
\text { Residual porosity } \\
\end{array}$ & $\begin{array}{l}\phi=\left(\phi_{0}-\phi_{r}\right) \exp \left(5 \cdot 10^{-8} \cdot \sigma_{M}^{\prime}\right)+\phi_{r} \\
\phi_{0}=0.1 \\
\phi_{r}=0.09\end{array}$ & $\begin{array}{l}\phi=\left(\phi_{0}-\phi_{r}\right) \exp \left(5 \cdot 10^{-8} \cdot \sigma_{M}^{\prime}\right)+\phi_{r} O \\
\phi_{0}=0.01 \\
\phi_{r}=0.009\end{array}$ \\
\hline $\begin{array}{l}\text { Permeability-porosity } \\
\text { function }\end{array}$ & $k=k_{0} \cdot 7 \cdot 10^{-10} \exp (222.0 \cdot \phi)$ & $k=k_{0} \cdot 7 \cdot 10^{-10} \exp (2220.0 \cdot \phi)$ \\
\hline Zero stress permeability & $k_{0}=110 . \mathrm{e}-13 \mathrm{~m}^{2}$ & $k_{0}=110 . \mathrm{e}-16 \mathrm{~m}^{2}$ \\
\hline $\begin{array}{l}\text { Corey's (1954) relative } \\
\text { permeability function }\end{array}$ & $\begin{array}{l}k_{r l}=\hat{S}^{4} \\
k_{r g}=(1-\hat{S})^{2}\left(1-\hat{S}^{2}\right) \\
\hat{S}=\frac{\left(S-S_{l r}\right)}{\left(1-S_{l r}-S_{g r}\right)}\end{array}$ & $\begin{array}{l}k_{r l}=\hat{S}^{4} \\
k_{r g}=(1-\hat{S})^{2}\left(1-\hat{S}^{2}\right) \\
\hat{S}=\frac{\left(S-S_{l r}\right)}{\left(1-S_{l r}-S_{g r}\right)}\end{array}$ \\
\hline Irreducible gas saturation & $S_{l g}=0.05$ & $S_{l g}=0.05$ \\
\hline Irreducible liq. saturation & $S_{l r}=0.3$ & $S_{l r}=0.3$ \\
\hline $\begin{array}{l}\text { van Genuchten's (1980) } \\
\text { capillary pressure function }\end{array}$ & $\begin{aligned} P_{c a p} & =-P_{0}\left(\left[S^{*}\right]^{-1 / \lambda}-1\right)^{1-\lambda} \\
S^{*} & =\left(S_{l}-S_{l r}\right) /\left(1-S_{l r}\right)\end{aligned}$ & $\begin{aligned} P_{c a p} & =-P_{0}\left(\left[S^{*}\right]^{-1 / \lambda}-1\right)^{1-\lambda} \\
S^{*} & =\left(S_{l}-S_{l r}\right) /\left(1-S_{l r}\right)\end{aligned}$ \\
\hline Irreducible liq. saturation & $S_{l r}=0.0$ & $S_{l r}=0.0$ \\
\hline Exponent & $\lambda=0.457$ & $\lambda=0.457$ \\
\hline Strength coefficient & $P_{0}=1.87 \mathrm{kPa}$ & $P_{0}=59.1 \mathrm{kPa}$ \\
\hline
\end{tabular}

d) Mean stress

e) Mean effective stress

f) Permeability

g) Porosity

h) Vertical displacement

These should be provided for the following times:

1) Initial (just before injection)

2) 1 day 
3) 1 year

4) 30 years (end of injection period)

5) 100 years

The following transient monitoring data should be provided as a function of time:

1) The injection rate.

2) The rate of $\mathrm{CO} 2$ flow $\left(\mathrm{kg} / \mathrm{sm}^{2}\right)$ at the top of caprock.

3) The rate of $\mathrm{CO} 2$ flow $\left(\mathrm{kg} / \mathrm{sm}^{2}\right)$ at the ground surface.

\section{COMPARISON CRITERIA}

Profiles at the same time should match within 5\%.

\section{REFERENCES}

Corey, A.T. The Interrelation Between Gas and Oil Relative Permeabilities, Producers Monthly, pp. 38 - 41, November 1954.

van Genuchten, M.Th. A Closed-Form Equation for Predicting the Hydraulic Conductivity of Unsaturated Soils, Soil Sci. Soc. Am. J., Vol. 44, pp. 892 - 898, 1980. 


\section{Test Problem 7: $\mathrm{CO}_{2}$ Injection into a 2-D Layered Brine Formation\#}

\section{INTRODUCTION AND GENERAL DESCRIPTION}

This test problem is patterned after the $\mathrm{CO}_{2}$ injection project at the Sleipner Vest field in the Norwegian sector of the North Sea, and is intended to investigate the dominant physical processes associated with the injection of supercritical $\mathrm{CO}_{2}$ into a layered medium. Significant simplifications have been made, the most important of which is the assumption of isothermal conditions $\left(37^{\circ} \mathrm{C}\right.$, the ambient temperature of the formation). $\mathrm{CO}_{2}$ injection rates $(1,000,000$ tonnes per year), system geometry, and system permeabilities correspond approximately to those at Sleipner, although no attempt was made to represent details of the permeability structure within the host formation. Injection of the supercritical $\mathrm{CO}_{2}$, which is less dense than the saline formation waters into which it is injected, causes it to rise through the formation. Its rate of ascent, however, is limited by the presence of four relatively low permeability shales. The top and bottom of the formation is assumed to be impermeable. The only reactive chemistry considered in this problem is the dissolution of $\mathrm{CO}_{2}$ in the aqueous phase.

\section{LIST OF PROCESSES BEING STUDIED}

a) Gravity-driven advection in response to strong vertical and lateral density gradients induced by the injection of $\mathrm{CO}_{2}$ into saline formation water.

b) Density, viscosity, and solubility formulations of water and $\mathrm{CO}_{2}$ as a function of pressure and temperature $(\mathrm{P}$ and $\mathrm{T})$.

\section{DEFINITION OF THE PROBLEM AND INPUT DATA}

\section{System Geometry:}

The system is idealized as a two dimensional symmetric domain perpendicular to the horizontal injection well which has a screen length of 100 meters (Figure 7.1). A one meter thick section perpendicular to the horizontal well is considered. The thickness of the formation at the injection site is 184 meters. The injection point is 940 meters below the sea floor, while the ocean depth at the site is 80 meters. The formation is assumed to consist of four lower permeability shale units 3 meters thick which are distributed within the high permeability sand. Each shale unit is separated by 30 meters. The well is 30 meters below the lowest shale unit, while the bottom of the aquifer is another 22 meters below the well.

\footnotetext{
\# proposed by Carl Steefel; e-mail: steefel1 @1lnl.gov
} 
Upper Shale Cap (impermeable)

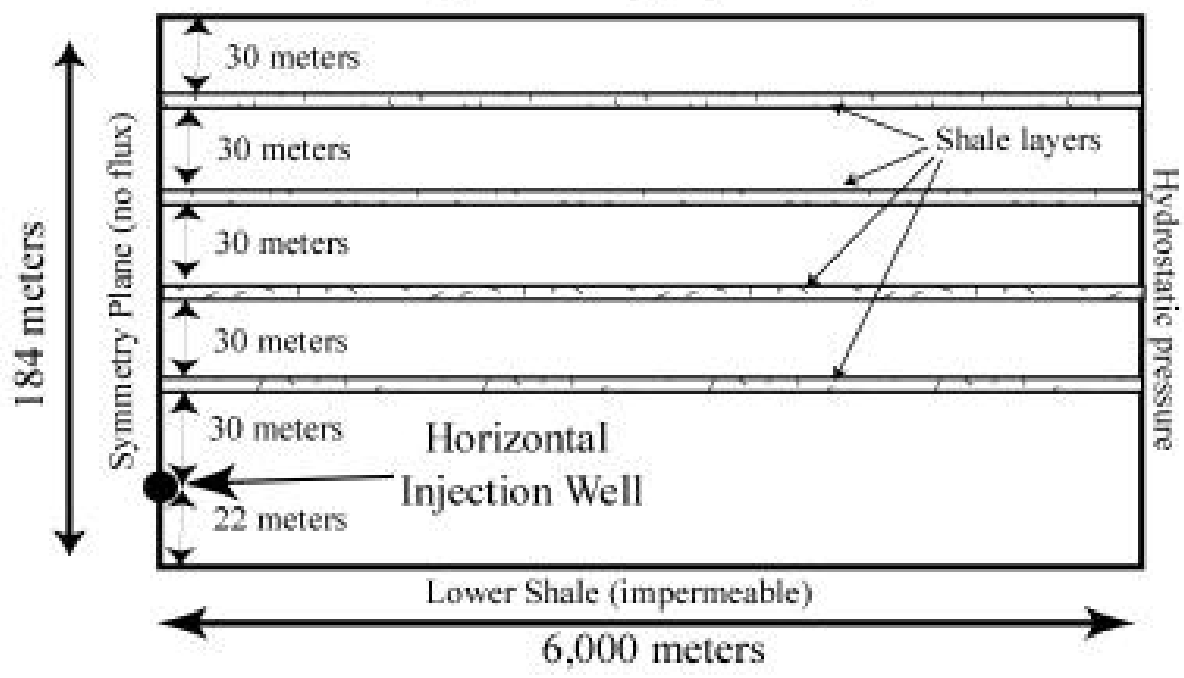

Figure 7.1 Schematic representation of geometry for CO2 injection in Utsira Formation.

\section{Boundary conditions:}

No heat or mass flux is allowed across any of the boundaries except the vertical boundary 6,000 meters from the injection well. This boundary is fixed at hydrostatic pressure, thus allowing flow into and out of the domain so as to avoid overpressuring the formation. The 6,000 meter boundary is chosen, however, to be far enough from the injection well that the $\mathrm{CO}_{2}$ does not reach this boundary after 2 years of injection.

\section{Initial conditions (Table 7.1):}

a) $\mathrm{T}=37{ }^{\circ} \mathrm{C}$ (isothermal throughout)

b) $\mathrm{P}=$ hydrostatic (approximately 110 bars at injection point, approximately 90 bars at top of formation).

c) $\mathrm{CO}_{2}$ in the aqueous phase in equilibrium with a $\mathrm{P}_{\mathrm{CO} 2}$ of 0.5 bars, a typical value for sedimentary formation waters at the temperature we are considering.

Table 7.1 Initial conditions and injection specifications

\begin{tabular}{|l|l|}
\hline Pressure at well & $110 \mathrm{bar}$ \\
\hline Temperature & $37{ }^{\circ} \mathrm{C}$ \\
\hline Salinity & $3.2 \mathrm{wt} .-\% \mathrm{NaCl}$ \\
\hline CO2 injection rate & $0.1585 \mathrm{~kg} / \mathrm{s}$ in half space \\
\hline
\end{tabular}


Injection specifications (Table 7.1):

a) Temperature $=37^{\circ} \mathrm{C}$

b) Injection rate: $31.7 \mathrm{~kg} / \mathrm{s}$ over entire screen length (100 meters), corresponding to $0.317 \mathrm{~kg} / \mathrm{s}$ for the 1 meter thick section considered. Because of symmetry, injection rate in half space is therefore $0.1585 \mathrm{~kg} / \mathrm{s}$.

c) Height of well cell: 1 meter.

d) Injection time scale: 2 years

Input data (Table 7.2):

a) Capillary pressure and relative permeability described with van Genuchten parameters (both liquid and gas mobile). Porosity is $35 \%$ for sands, $10.25 \%$ for shales.

b) Fully saturated permeability ( $\mathrm{k}=3 \times 10^{-12} \mathrm{~m}^{2}$ in sand layers, $10^{-14} \mathrm{~m}^{2}$ in shales)

c) Density, viscosity, and solubility in water of $\mathrm{CO}_{2}$ as functions of $\mathrm{P}$ and $\mathrm{T}$ (Span and Wagner, 1996).

d) Vapor-liquid equilibrium properties of water.

\section{PROBLEM VARIATIONS}

Include non-isothermal effects by making the $\mathrm{CO}_{2}$ injection temperature equal to $65^{\circ} \mathrm{C}$.

\section{RESULTS TO BE CALCULATED}

Liquid and gas saturations as a function of space and time. $\mathrm{CO}_{2}$ concentration in the aqueous phase as a function of space. Gas and liquid fluxes.

\section{COMPARISON CRITERIA}

Results should match within $+/-5 \%$. 
Table 7.2 Hydrogeologic parameters

\begin{tabular}{|c|c|}
\hline $\begin{array}{l}\text { Permeability } \\
\text { Porosity } \\
\text { Aquifer thickness }\end{array}$ & $\begin{array}{l}\text { Sands: } 3 \times 10^{-12} \mathrm{~m}^{2} \text {; Shales: } 10^{-14} \mathrm{~m}^{2} \\
\text { Sands: } \phi=0.35 \text {; Shales: } \phi=0.1025 \\
184 \mathrm{~m}\end{array}$ \\
\hline Relative permeability & \\
\hline $\begin{array}{l}\text { liquid: van Genuchten function (1980) } \\
k_{r l}=\sqrt{S^{*}}\left\{1-\left(1-\left[S^{*}\right]^{1 / \lambda}\right)^{\lambda}\right\}^{2} \\
\text { irreducible water saturation } \\
\text { exponent }\end{array}$ & $\begin{array}{l}S^{*}=\left(S_{l}-S_{l r}\right) /\left(1-S_{l r}\right) \\
S_{l r}=0.20 \\
\lambda=0.400\end{array}$ \\
\hline $\begin{array}{l}\text { gas: van Genuchten function (1980) } \\
k_{r g}=\sqrt{S_{g}^{*}}\left\{1-\left(1-\left[S_{g}^{*}\right]^{1 / \lambda}\right)^{\lambda}\right\}^{2} \\
\text { irreducible gas saturation } \\
\text { exponent }\end{array}$ & $\begin{array}{l}S_{g}^{*}=\left(S_{g}-S_{g r}\right) /\left(1-S_{g r}\right) \\
S_{\mathrm{gr}}=0.05 \\
\lambda=0.400\end{array}$ \\
\hline Capillary pressure & \\
\hline $\begin{array}{l}\text { van Genuchten function (1980) } \\
P_{\text {cap }}=-P_{0}\left(\left[S^{*}\right]^{-1 / \lambda}-1\right)^{1-\lambda} \\
\text { irreducible water saturation } \\
\text { exponent } \\
\text { strength coefficient }\end{array}$ & $\begin{array}{l}S^{*}=\left(S_{l}-S_{l r}\right) /\left(1-S_{l r}\right) \\
S_{l \mathrm{r}}=0.20 \\
\lambda=0.400 \\
\text { Sand: } \mathrm{P}_{0}=3.58 \mathrm{kPa} ; \text { Shale: } \mathrm{P}_{0}=62.0 \mathrm{kPa}\end{array}$ \\
\hline
\end{tabular}

\section{REFERENCES}

van Genuchten, M.Th. A Closed-Form Equation for Predicting the Hydraulic Conductivity of Unsaturated Soils, Soil Sci. Soc. Am. J., Vol. 44, pp. 892 - 898, 1980.

Span, R. and W. Wagner. A New Equation of State for Carbon Dioxide Covering the Fluid Region from the Triple-Point Temperature to $100 \mathrm{~K}$ at Pressures up to $800 \mathrm{MPa}$, J. Phys. Chem. Ref. Data, Vol. 25, No. 6, pp. 1509 - 1596, 1996. 


\section{Test Problem 8. CO2-Oil Displacement and Phase Behavior ${ }^{1}$}

\section{INTRODUCTION AND GENERAL DESCRIPTION}

This problem probes our ability to predict accurately the interplay of $\mathrm{CO}_{2}$-oil phase behavior and multiphase flow. $\mathrm{CO}_{2}$ is injected into an oil-containing medium under two different conditions leading to miscible and immiscible displacement. This initial problem is posed in a one-dimensional geometry so that direct comparison can be made to available analytical solutions that have been derived for the $\mathrm{CO}_{2}$-oil flow problem (Monroe et al. 1990, Orr et al. 1993). These solutions do not include the effects of capillary and hydrodynamic dispersion, but the effect of volume change on mixing will be computed.

\section{LIST OF PROCESSES BEING STUDIED}

Multiphase flow of $\mathrm{CO}_{2}$ and oil subject to relative permeability and phase behavior effects.

Development of miscibility in $\mathrm{CO}_{2}$-oil systems.

Numerical formulations for density, viscosity, and $\mathrm{CO}_{2}$ solubility in oil.

Degree of numerical dispersion in numerical solutions.

\section{DEFINITION OF THE PROBLEM AND INPUT DATA}

- Oil composition: $10 \% \mathrm{CH}_{4}, 20 \% \mathrm{C}_{4}$, and $70 \% \mathrm{C}_{10}$.

- Injected gas composition: $100 \% \mathrm{CO}_{2}$

- Injection P: case (a) $\mathrm{P}=11.0 \mathrm{MPa}$ and case (b) $\mathrm{P}=12.0 \mathrm{MPa}$.

- Injection condition: constant volumetric rate

- Temperature: $\mathrm{T}=71.1^{\circ} \mathrm{C}$ and isothermal throughout.

- Geometry: one dimensional.

- Permeability and porosity: comparisons will be made in nondimensional form and so need not be specified.

- Relative permeability: $\mathrm{k}_{\mathrm{rg}}=\left(\frac{\mathrm{S}_{\mathrm{g}}}{1-\mathrm{S}_{\mathrm{or}}}\right)^{2} ; \mathrm{k}_{\mathrm{ro}}=\left(\frac{1-\mathrm{S}_{\mathrm{g}}-\mathrm{S}_{\mathrm{or}}}{1-\mathrm{S}_{\mathrm{or}}}\right)^{2}$ where $\mathrm{S}_{\mathrm{or}}=0.2$

- Phase behavior: Reference results will be computed from the Peng-Robinson equation of state (Peng and Robinson, 1976) with the critical properties, volume corrections, and interaction coefficients tabulated by Orr et al. (1993). For comparison purposes, any phase behavior package can be employed.

\section{PROBLEM VARIATIONS}

Extend to more than 4 components to examine degree of chromatographic separation of various components. Include other combustion gases and $\mathrm{N}_{2}$ in the injection gas. Examine the accuracy of prediction of the minimum miscibility pressure.

\section{DEFINITION OF RESULTS TO BE CALCULATED}

Saturation and composition profiles along the one-dimensional medium. For consistency the abscissa should be $\mathrm{x}_{\mathrm{D}} / \mathrm{t}_{\mathrm{D}}$ where the dimensionless distance, $\mathrm{x}_{\mathrm{D}}$, is defined as $\mathrm{x} / \mathrm{L}$, the dimensionless time, $\mathrm{t}_{\mathrm{D}}$, is $\mathrm{q}_{\mathrm{inj}} \mathrm{t} / \mathrm{\phi AL}$, and $\mathrm{A}$ is the cross-sectional area of the medium.

\section{COMPARISON CRITERIA}

Profiles should reproduce the location of saturation and composition shocks within $\pm 5 \%$.

\footnotetext{
1 proposed by Tony Kovscek; email: kovscek@ pangea.stanford.edu
} 


\section{REFERENCES}

Monroe, W.W., M.K. Silva, L.L. Larson, and F. M. Orr, Jr., 1990, Composition Paths in Four Component Systems: Effect of Dissolved Methane on $1 \mathrm{D} \mathrm{CO}_{2}$ Flood Performance, SPE Res. Eng., Aug, 423-432.

Orr, F, M, Jr., R. T. Johns, and B. Dindoruk, 1993, Development of Miscibility in Four-Component $\mathrm{CO}_{2}$ Floods, SPE Res. Eng., May, 135-142.

Peng, D. Y. and D. B. Robinson, 1976, A New Two Constant Equation of State, Ind. Eng. Chem. Fund., 15, 59-64. 